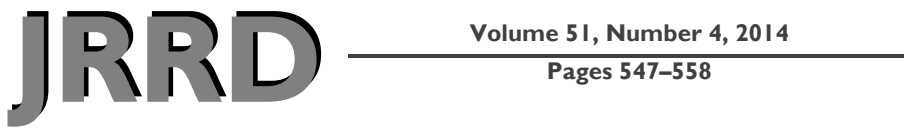

\section{Visual function, traumatic brain injury, and posttraumatic stress disorder}

\author{
Gregory L. Goodrich, PhD; ${ }^{1 *}$ Gary L. Martinsen, OD, PhD; ${ }^{1}$ Heidi M. Flyg, OD; ${ }^{1}$ Jennine Kirby, OD; $^{1}$ Donn \\ W. Garvert, MS $^{\mathbf{1}}$; Christopher W. Tyler, PhD, DSc ${ }^{2}$ \\ ${ }^{1}$ Department of Veterans Affairs Palo Alto Health Care System, Palo Alto, CA; ${ }^{2}$ Smith-Kettlewell Eye Research Insti- \\ tute, San Francisco, CA
}

\begin{abstract}
Traumatic brain injury (TBI) and posttraumatic stress disorder (PTSD) are signature injuries of the Iraq and Afghanistan conflicts. The conditions can be comorbid and have overlapping signs and symptoms, making it difficult to diagnose and treat each. TBI is associated with numerous changes in vision function, but vision problems secondary to PTSD have not been documented. To address this shortcoming, we reviewed the medical records of 100 patients with a history of TBI, noting PTSD diagnoses, visual symptoms, vision function abnormalities, and medications with visual side effects. Forty-one patients had PTSD and 59 did not. High rates of binocular vision and oculomotor function deficits were measured in patients with a history of TBI, but no significant differences between patients with or without PTSD were evident. However, compared to patients without PTSD, patients with PTSD had more self-reported visual symptoms in all four assessments and the complaint rates were significantly higher for light sensitivity and reading problems. Together, these findings may be beneficial in understanding vision problems in patients with TBI and PTSD as comorbid conditions compared with those with TBI alone.
\end{abstract}

Key words: binocular vision, blast-related, medication side effects, non-blast-related, oculomotor function, posttraumatic stress disorder, traumatic brain injury, vision function, vision loss, visual symptoms.

\section{INTRODUCTION}

Posttraumatic stress disorder (PTSD) is a serious mental health condition that can develop after exposure to events such as assault or disaster. Documentation of
PTSD-like psychological conditions from battle dates back thousands of years, at least as early as the GrecoPersian wars [1]. In the 17th century, military physicians began to assign terms such as "nostalgia" and "homesickness" to war-related psychological disorders. Much like the symptoms of PTSD today, these conditions were characterized by insomnia, weakness, anxiety, palpitations, stupor, and depression. In the American Civil War, the terms "soldier's heart" and "exhausted heart" were given to soldiers with symptoms similar to those of PTSD [2]. In World War I, many soldiers with psychiatric symptoms due to combat were said to have "shell shock," which was thought to be caused by physiological changes secondary to proximity to artillery explosions [2]. This view changed only when military physicians recognized

\footnotetext{
Abbreviations: $\mathrm{BR}=$ blast-related, $\mathrm{BV}=$ binocular vision, $\mathrm{CI}=$ convergence insufficiency, $\mathrm{GCS}=$ Glasgow Coma Scale, IED = improvised explosive device, $\mathrm{LOC}=$ loss of consciousness, $\log \mathrm{MAR}=$ logarithm minimum angle of resolution, $\mathrm{mTBI}=$ mild traumatic brain injury, $\mathrm{NBR}=$ non-blast-related, $\mathrm{NPC}=$ near point of convergence, $\mathrm{OEF}=$ Operation Enduring Freedom, OIF $=$ Operation Iraqi Freedom, PTA $=$ posttraumatic amnesia, $\mathrm{PTSD}=$ posttraumatic stress disorder, RPG $=$ rocket propelled grenade, $\mathrm{TBI}=$ traumatic brain injury, $\mathrm{VA}=$ visual acuity.

*Address all correspondence to Gregory L. Goodrich, PhD; Department of Veterans Affairs Palo Alto Health Care System, 795 Willow Road Bldg T-365, Menlo Park, CA 94025; 650-493-5000, ext 24640; fax: 650-614-9955.
}

Email: Gregory.Goodrich@va.gov

http://dx.doi.org/10.1682/JRRD.2013.02.0049 
that not all troops affected by shell shock were exposed to artillery blasts. Thousands of U.S. soldiers involved in the conflicts in Korea and Vietnam experienced psychological symptoms [1-2] including distressing memories and nightmares. Psychological injury occurred in troops both with and without physical injuries. The term "PTSD" was added to the lexicon in the early 1980s [3] to describe these psychological symptoms and problems that frequently result from war trauma. As in previous conflicts, psychological injury arising from the wars in Afghanistan and Iraq is well documented [4]. The prevalence of PTSD in combat troops who served in Operation Iraqi Freedom (OIF) is estimated to be between 10 and 18 percent, a rate that does not diminish with the passage of time [4].

PTSD is an anxiety disorder that is characterized by intrusive memories of the traumatic event, avoidance behaviors, and hyperarousal [5]. PTSD stems from at least two factors: a traumatic experience and the individual reaction to the event (per Diagnostic and Statistical Manual of Mental Disorders IV criteria) [6]. Experiencing or witnessing a traumatic incident, such as an automobile accident or a battlefield explosion, can trigger PTSD in some individuals. However, not everyone will develop PTSD from a traumatic event. For individuals who experience the same traumatic event, some may go on to develop PTSD, while others may not [3].

Several criteria concerning a person's exposure and reaction to a traumatic event must have occurred for a diagnosis of PTSD to be made [6]. The criteria include (1) exposure to a traumatic event; (2) intrusive recollection of the event through distressing memories, disturbing dreams, and other ways; (3) avoidance/numbing behavior, including avoidance of associated thoughts and places and diminished interest in activities; (4) at least two symptoms indicating hyperarousal, including sleep dysfunction, irritability, hypervigilance, and an exaggerated startle response; and (5) duration of symptoms of more than 1 mo. Additionally, the symptoms should be associated with significant distress in social function, occupational function, or other areas [5-6].

As with PTSD, traumatic brain injury (TBI) is not exclusive to the military, but it is frequently associated with warfare. The incidence of TBI from the recent conflicts in Iraq and Afghanistan has increased compared with previous wars. For this reason, TBI and PTSD have been called the signature injuries of these wars [7], bringing increased attention to these two conditions. Com- pared with previous conflicts, the heavy use of improvised explosive devices (IEDs), mines, rocket propelled grenades (RPGs), and other explosives has put many troops in harm's way from blasts. Accordingly, studies have shown that blast-related (BR) injures comprise 56 to 78 percent of all injuries sustained by U.S. troops in the Global War on Terrorism [8-9]. Improvements in body armor have reduced mortality rates from thoracic injury [10-11]. However, the head, face, and neck are still relatively exposed and the incidence of injury to these areas has actually increased in OIF/Operation Enduring Freedom (OEF) troops [12]. As expected, the rise in head injuries has been accompanied by escalated rates of TBI. Additionally, improvements in military medicine have improved survival rates, thereby increasing the number of troops and veterans living with TBI and other wounds.

The Department of Veterans Affairs/Department of Defense define TBI as "a traumatically induced structural injury and/or physiological disruption of brain function as a result of an external force that is indicated by new onset or worsening of at least one of the following clinical signs, immediately following the event - any period of loss of or a decreased level of consciousness (LOC), any loss of memory for events immediately before or after the injury (posttraumatic amnesia [PTA]), any alteration in mental state at the time of the injury (confusion, disorientation, slowed thinking, etc.), neurological deficits (weakness, loss of balance, change in vision, praxis, paresis/plegia, sensory loss, aphasia, etc.) that may or may not be transient, and/or intracranial lesion" [13]. TBI is categorized as "mild," "moderate," "severe," or "penetrating" depending on the extent and type of injury and the physical signs that occur at the time of injury. The diagnosis of mild TBI (mTBI) after head trauma requires at least one of the following - LOC lasting from 0 to 30 min, PTA of less than $24 \mathrm{~h}$, a Glasgow Coma Scale (GCS) score of 13 to 15 , and any alteration of consciousness/mental state following the event lasting from a moment up to $24 \mathrm{~h}$ [13-14]. Moderate TBI diagnosis is made by LOC of over $30 \mathrm{~min}$ but less than $24 \mathrm{~h}$, PTA greater than $1 \mathrm{~d}$ but less than $7 \mathrm{~d}$, and an initial GCS score of 9 to 12. A severe TBI diagnosis is made when LOC exceeds $24 \mathrm{~h}$, PTA exceeds $7 \mathrm{~d}$, and the GCS score is less than 9 [15]. A penetrating TBI is caused by a foreign body penetrating the brain [13]. All severity levels of TBI are associated with physical, psychological, and 
social complications that can be short-term or chronic [16-17].

Many troops and veterans with TBI also develop PTSD. In the past, this was considered improbable because TBI-associated altered consciousness and amnesia should prevent the encoding of memories considered necessary for PTSD development [18-19]. Supporting this dissociation is evidence that PTSD occurs more frequently in mTBI than in moderate or severe TBI [18]. This might occur because mTBI-associated PTA is shorter and less severe than PTA in moderate/severe TBI. However, PTSD is diagnosed in some patients with moderate/severe TBI and, in these patients, PTSD might arise because the PTA was only partial and some memories of the event remain [19]. It might also develop from reconstructed memories from photos or conversations with witnesses. Additionally, memories of events after the trauma, such as painful medical procedures, might be sufficient to induce PTSD in some individuals [18]. Complicating the coexistence of TBI and PTSD is the fact that symptoms from each condition often overlap. Overlapping symptoms include irritability, sleep problems, problems with concentration and memory, fatigue, and pain [5,19-20]. Thus, in persons with both conditions, it may become difficult to ascribe a symptom to a specific diagnosis. This can complicate selection of treatment alternatives because treatment of PTSD, a psychological disorder, might differ from treatment of TBI, which is attributed to organic neural changes.

Adverse changes in vision function and increases in visual symptoms have been documented in TBI, and many of these problems may be due to brain injury in areas associated with ocular function [21-23]. To the authors' knowledge, vision problems in patients with PTSD have yet to be documented in the literature. There have been anecdotal reports of increased light sensitivity in patients with PTSD and an Internet search has yielded many discussions in this area, but research examining this association could not be found. Increased multisensory symptoms including visual, hearing, and vestibular problems have been reported in OIF/OEF veterans with PTSD, but no specific analyses linking only visual symptoms to PTSD were made [24]. This lack of information leads to speculation about what vision changes might occur in patients with PTSD. It might be that oculomotor and binocular vision (BV) dysfunctions occur less frequently in PTSD than in TBI because PTSD is a psychological injury and normal ocular function might not be affected. Conversely, the concentration difficulties, irritability, depression, social detachment, and other psychological problems in PTSD [20] might contribute to poor results during vision testing. Herein, we report on the results of vision tests in patients with a history of TBI, both with and without PTSD, to provide new insights about vision issues in both conditions.

\section{METHODS}

In this retrospective study, we reviewed electronic medical records of inpatients seen by the Optometry department in the Polytrauma Rehabilitation Clinic at the Department of Veterans Affairs Palo Alto Health Care System. We enrolled 50 patients who sustained a non-BR (NBR)-TBI from events such as automobile accidents or falls and 50 who sustained a BR-TBI from proximity to an explosive blast. Among the patients with NBR-TBI, 46 were on Active Duty when injured and 4 were veterans eligible for Department of Veterans Affairs medical care. Two incurred NBR-TBI while stationed in Iraq, but most were injured in the United States. All patients with a history of BR-TBI were on Active Duty and stationed in Iraq or Afghanistan when injured.

It was not possible to determine exactly which type of BR injury each patient with BR-TBI had. Blast injury can occur directly from the blast energy or indirectly from events surrounding the blast and has differing terminology depending on the cause [25]. Primary BR-TBI occurs directly from exposure to blast pressure waves. Secondary injury is caused when projectiles energized by the blast impact a person. These projectiles can cause blunt trauma as well as penetrating brain injury. Tertiary injury occurs when a person, hurled by a blast, hits a solid object. Quaternary injury is blast-related injury not due to primary, secondary, or tertiary events and includes crush injuries, burns, fume poisonings, and other causes. Prior research has indicated that most cases of BR-TBI are not due to an isolated mechanism but are caused by a combination of these factors [26-27].

\section{Posttraumatic Stress Disorder Diagnosis}

All 41 veterans with PTSD had a confirmed diagnosis made by a mental health provider and recorded in their electronic medical record. All other patients were classified as not having PTSD. Other psychological diagnoses such as depression and mood disorder were common in 
patients with and without PTSD and were noted when present. Additionally, many patients were on medications for both physical and psychological conditions. Any medication with visual side effects was documented.

\section{Traumatic Brain Injury Severity}

TBI severity was classified as either mild or moderate/severe based on information in the electronic medical record. Documentation of TBI severity, by a Polytrauma Rehabilitation Center physician, was used whenever present. If this information was unavailable, a determination of TBI severity was made using standard classification criteria [13] by one of the authors (GLM) based on information in the electronic medical record.

\section{Vision and Ocular Data}

Vision data, both self-reported vision complaints and testing results, were collected from the first full eye/vision examination record after the patient's TBI-inducing event. Some data were not available in every record because some patients could not complete all testing. In addition, some testing was not feasible in certain patients (e.g., convergence was not assessed in patients who were monocular). All eye/vision examinations were conducted by optometrists with expertise in the evaluation and treatment of patients with TBI.

The chief complaint and history sections of each patient's eye examination record were examined to determine the presence or absence of self-reported visual symptoms. Any complaints of light sensitivity, blurred vision, reading symptoms, or diplopia were documented. If any information could not be ascertained, it was recorded as missing data. Visual acuity (VA) was measured with a Feinbloom Distance Low-Vision chart in nonambulatory patients and in eyes with very poor vision. In all others, VA was measured with an Early Treatment Diabetic Retinopathy Study acuity chart. Fixation was tested by having the patient fixate a 20/50 near target. Any observed fixation unsteadiness or nystagmus during the testing was recorded as a fixation deficit. Northeastern State University Oklahoma College of Optometry oculomotor norms were used to evaluate pursuits and saccades [28]. The examiner recorded if pursuit and saccadic testing results were normal or deficient but did not document individual parameters. Cover testing, both unilateral and alternate, was conducted in primary gaze at distance and near. If the patient had trouble fixating, ocular alignment was assessed with the Hirschberg test. The near point of convergence (NPC) for binocular fusion was measured with the patient fixating a single 20/ 50 near letter. An NPC of greater than $8 \mathrm{~cm}$ was classified as convergence insufficiency (CI). Accommodative amplitude was tested monocularly on patients $40 \mathrm{yr}$ of age and younger with the pull-away technique and rated as normal or deficient using age-established norms [29]. Monocular visual fields were evaluated using confrontation, tangent screen, arc, or Goldmann perimetry, depending on the patient's abilities. Any visual field defect was diagrammed on a form appropriate to the test (e.g., Goldmann perimeter chart), scanned into the medical record, and described by the examiner.

Objectively measured reading ability was tested using internally developed reading materials [22]. The test was written at a sixth grade level and consisted of continuous text (10 point, Times New Roman font). Reading speed was noted and comprehension assessed by asking five questions about the information in the text. Reading facility was assessed subjectively. The examiner recorded if the patient's reading ability was normal or if a reading deficit was present based on the test results.

The presence and extent of any ocular injury was assessed via a thorough history and a complete anterior and posterior segment ocular heath examination.

\section{Analysis}

Data analyses were conducted using SPSS software, version 18 (IBM Corporation; Armonk, New York). Univariate analyses were performed using $\chi^{2}$ and Fisher exact tests for binary variables. Fisher exact test was used in cases where the expected value for any cell was less than five [30]. A $t$-test was used for continuous variables. Logistic regression was used to examine the relationship of PTSD to the observed results while controlling for possible confounding variables.

\section{RESULTS}

Table 1 gives demographic data of the 100 patients whose records were reviewed. All had a history of TBI: 50 NBR- and 50 BR-TBI. Of the patients, 41 had a PTSD diagnosis and 59 did not. The average age of the patients with PTSD was approximately $6.5 \mathrm{yr}$ greater than the patients without PTSD, and this difference was significant: $t(98)=3.17, p=0.002$. Only five females were included, and the sex distribution was nearly equal in 
Table 1.

Patient demographics. Data shown at $n(\%)$ unless otherwise indicated.

\begin{tabular}{|c|c|c|}
\hline Demographic & $\begin{array}{l}\text { With PTSD } \\
(n=41)\end{array}$ & $\begin{array}{l}\text { Without PTSD } \\
\quad(n=59)\end{array}$ \\
\hline \multicolumn{3}{|l|}{$\overline{\text { Age* }^{*}(\mathrm{yr})}$} \\
\hline Mean & 32.83 & 26.37 \\
\hline Range & $19-59$ & $19-63$ \\
\hline \multicolumn{3}{|l|}{ Sex } \\
\hline Male & $39(95)$ & $56(95)$ \\
\hline Female & $2(5)$ & $3(5)$ \\
\hline \multicolumn{3}{|l|}{ TBI Type ${ }^{\dagger}$} \\
\hline Mild & $21 / 40$ & $6 / 58^{\ddagger}(10)$ \\
\hline Moderate/Severe & $19 / 40+(48)$ & $52 / 58^{\ddagger}(90)$ \\
\hline \multicolumn{3}{|l|}{ TBI Mechanism $^{\dagger}$} \\
\hline NBR & $10(24)$ & $40(68)$ \\
\hline $\mathrm{BR}$ & $31(76)$ & $19(32)$ \\
\hline Penetrating TBI & $1(2.4)$ & $8(14)$ \\
\hline Eye/Orbit Trauma & $8 / 40^{\ddagger}(20)$ & $21 / 58+(36)$ \\
\hline Monocular & $0(0)$ & $6(10)$ \\
\hline $\begin{array}{l}{ }^{*} p=0.002 . \\
{ }^{\dagger} p<0.001 . \\
\text { tReduced sample size due } \\
\text { BR = blast-related, NBR } \\
\text { order, TBI = traumatic br: }\end{array}$ & $\begin{array}{l}\text { iissing data. } \\
\text {-blast-related, PTSL } \\
\text { jury. }\end{array}$ & osttraumatic stress dis- \\
\hline
\end{tabular}

each group. Of the 41 patients with PTSD, 31 sustained BR-TBI and 10 NBR-TBI, and this difference was significant: $\chi^{2}(1)=16.54, p<0.001$. Mild TBI was significantly associated with PTSD in this patient sample $\left(\chi^{2}(1)=\right.$ $19.02, p<0.001)$ since 53 percent of patients with PTSD and 10 percent of patients without PTSD had a history of mTBI. In our sample, the nine patients with a penetrating TBI also had a diagnosis of moderate/severe TBI and are included in both groups. Penetrating TBI, being monocular, and a history of trauma to the eye or orbit occurred with greater frequency in the patients without PTSD, but the differences were not significant. A visual field defect was found in 5 of $41(12 \%)$ patients with PTSD and in 7 of $58(12 \%)$ patients without PTSD.

All of the patients in this study had relatively good VAs in at least one eye. The average logarithm minimum angle of resolution (logMAR) VA* from each patient's best eye was 0.022 ( 20/21 Snellen equivalent). The average VAs for those with and without PTSD (0.01 [20/ $20]$ and 0.03 [20/21], respectively) were not significantly different. Overall, the VAs from the best eyes ranged from $-0.10(20 / 16)$ to $0.40(20 / 50)$. Only 6 patients had best eye VAs in the $20 / 40$ to $20 / 50$ range, 2 of $41(5 \%)$ with and 4 of $59(7 \%)$ without PTSD. Another acuity metric, VA in the poorer eye, has the potential to capture the deleterious effects of ocular injury, TBI, and other stressors on vision. For each patient, VA in the poorer eye was assigned to one of two categories: (1) VA better than $0.54(20 / 70)$ or (2) VA equal to $20 / 70$ or worse. The $20 /$ 70 or worse category included eyes that were enucleated and those that were functionally blind in addition to those with poor VA. Four patients had VA reduction in one eye from childhood amblyopia, and the VA from the other eye was used in these cases. Three of $41(7.3 \%)$ patients with PTSD had an eye with poor acuity, compared with 9 of $59(15.3 \%)$ patients without PTSD. This difference was not significant: Fisher exact test, $p=0.36$.

Table 2 details the events that created injury sufficient to require hospitalization and/or medical care in these patients. This was the most recent TBI-associated event, although each may have sustained TBI earlier in their lifetimes. Most patients were injured in Iraq or Afghanistan (52\%). Forty percent were injured in the

Table 2.

Traumatic brain injury causes (last event) and association with posttraumatic stress disorder (PTSD), $n$.

\begin{tabular}{lcc}
\hline \multicolumn{1}{c}{ Cause } & $\begin{array}{c}\text { With PTSD } \\
(\boldsymbol{n}=\mathbf{4 1})\end{array}$ & $\begin{array}{c}\text { Without PTSD } \\
(\boldsymbol{n}=\mathbf{5 9})\end{array}$ \\
\hline Blast-Related & & \\
IED & 22 & 15 \\
RPG & 2 & 3 \\
Mortar & 3 & 0 \\
Blast & 4 & 1 \\
Non-Blast-Related & & \\
MVA & 4 & 11 \\
MCA & 1 & 10 \\
Fall & 2 & 9 \\
Assault & 2 & 4 \\
Other & 1 & 6 \\
\hline
\end{tabular}

Blast $=$ no specific mechanism documented, IED $=$ improvised explosive device, $\mathrm{MCA}=$ motorcycle accident, $\mathrm{MVA}=$ motor vehicle accident, $\mathrm{RPG}=$ rocket propelled grenade.

\footnotetext{
*VAs were recorded in logMAR format to facilitate statistical analysis. The minimum angle of resolution refers to the smallest feature that can be resolved on an acuity chart. For example, each horizontal bar and space of the letter "E" on a 20/20 line of a visual acuity chart subtends an angle of 1 arc minute (1/60 of a degree) at the eye when viewed from the correct distance. If a person's VA is 20/20, his or her minimum angle of resolution is 1 arc minute. The logarithm of 1 is 0 ; therefore, a person with 20/20 Snellen VA has a logMAR VA of 0 .
} 
United States, and the remainder while serving in Italy $(3 \%)$, Okinawa $(2 \%)$, Germany $(1 \%)$, Guam $(1 \%)$, or Turkey (1\%). In the BR-TBI group, all 50 subjects had injuries from a blast event caused by an IED, RPG, mortar, or mine. All blast injuries occurred in Afghanistan or Iraq. Injury in the NBR group was due to motor vehicle accident $(58 \%)$, fall $(16 \%)$, assault $(12 \%)$, pedestrian struck by vehicle (4\%), gunshot (4\%), bicycle accident (4\%), or snowboard accident (2\%). Most of the NBR injuries $(n=40)$ occurred in the United States, two occurred in Iraq, and the remaining eight occurred in Japan, Germany, Italy, Guam, or Turkey. The mechanism of injury in the 41 patients diagnosed with PTSD differed from the overall population. The mechanisms were blast event $(73 \%)$, motor vehicle accident $(15 \%)$, fall or assault $(10 \%)$, and gunshot $(2 \%)$. While the mechanism of injury represents the proximate cause of injury, it may or may not be the proximate cause of PTSD. Different factors of the blast event may have caused the TBI (e.g., blast wave, blunt trauma) and the PTSD (e.g., the condition of nearby companions). Moreover, subject medical records sometimes reported prior blast events and other traumatic exposures, which may have caused PTSD or contributed to its development.

The interval between date of injury and admission date ranged from approximately 2 wk to 56 mo with a mean interval of 8.0 mo. The interval between patient admission to the Polytrauma Rehabilitation Center and the vision examination varied depending on the patients' ability to participate in the examination. In the majority of cases, the interval between admission and examination was 1 to 4 mo. Patients with PTSD averaged longer intervals between injury and admission dates than those without PTSD. The means were 15.3 and 2.9 mo, respectively, and this difference was significant: $t(98)=$ $6.11, p<0.001$.

The percentages of oculomotor/BV deficits in veterans with and without PTSD are shown in Figure 1. Strabismus was more frequent in patients without PTSD (46\%) than in those with PTSD (26\%) but did not reach significance: $\chi^{2}(1)=2.78, p=0.10$. Additionally, no significant differences between the veterans with and without PTSD were found for any of the other oculomotor/ BV measures reported. Across all 100 patients, high rates of CI (63\%), accommodative insufficiency $(67 \%)$, and saccadic dysfunction $(71 \%)$ were found. Pursuit abnormalities (37\%) and fixation deficits (23\%) were less frequent but still noteworthy.
The frequencies of self-reported vision symptoms and reading performance deficits are shown in Figure 2. Overall, 79 of the 100 patients had one or more complaints about their vision. For all four visual symptom categories, patients with PTSD reported more problems than those without PTSD. The visual symptoms category in Figure 2 included complaints of blurred vision, hazy vision, and other general visual symptoms. Seventy-six percent of patients with PTSD and 61 percent of patients without PTSD reported visual symptoms, although this difference was not significant: $\chi^{2}(1)=1.72, p=0.19$. Documentation of light sensitivity assessment could be found in 86 patient records; these data were missing from 14 records. A higher percentage of patients with PTSD endorsed light sensitivity than those without PTSD (78\% vs $27 \%$ ), and the difference was significant: $\chi^{2}(1)=$ 23.08, $p<0.001$. A higher proportion of patients with PTSD also reported reading difficulties: $\chi^{2}(1)=8.36, p=$ 0.004 .

All but two of the patients in this study were on one or more medications to treat their physical and psychological injuries. Virtually every medication has side effects, and 85 percent of the patients were taking at least one medication with a visual side effect [31]. Table 3 lists each medication, its primary use, visual side effects, and the number of patients taking it. Thirty-nine of the 41 (95\%) veterans with PTSD and 46 of the 59 (78\%)

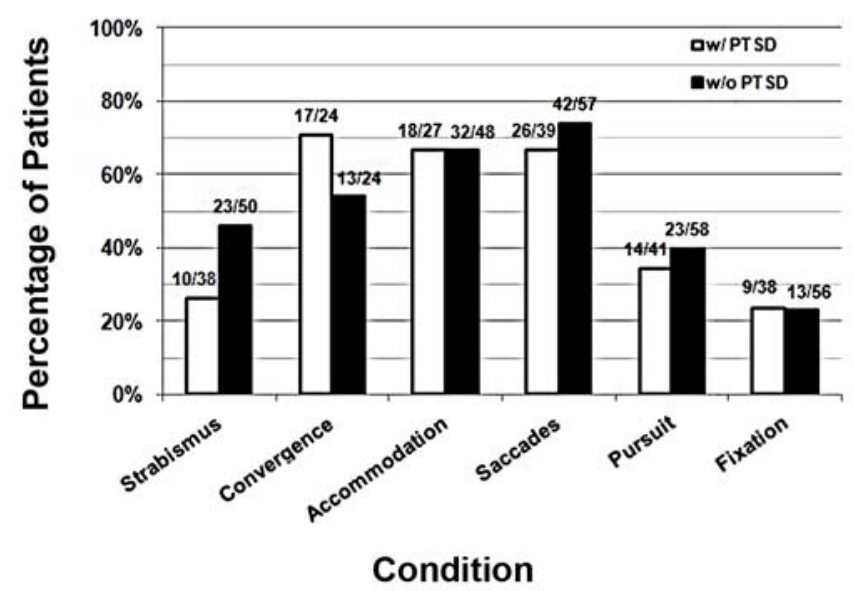

Figure 1.

Oculomotor and binocular vision deficits in patients with and without posttraumatic stress disorder (PTSD). Number of patients with each condition/total number of patients sampled is above each bar. 


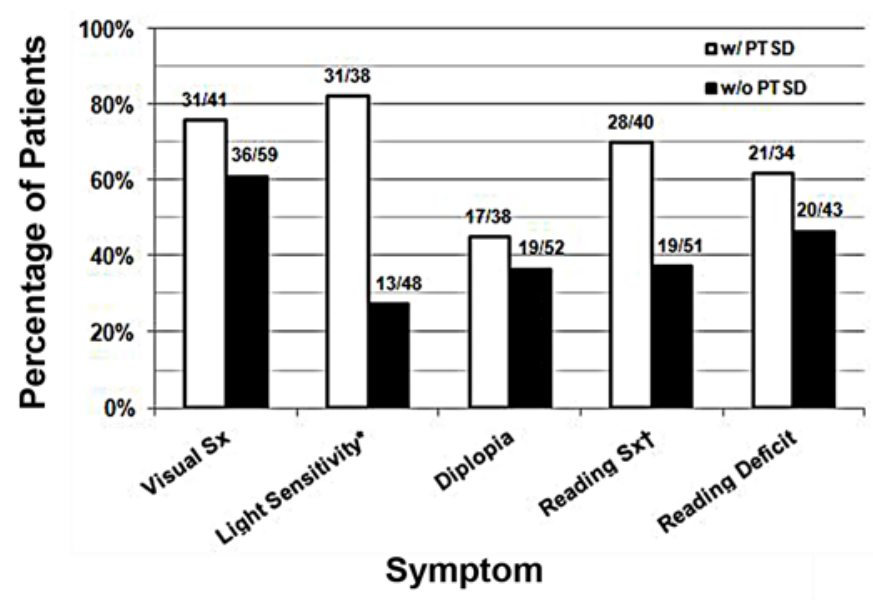

Figure 2.

Subjective visual symptoms (Sx) and objectively measured reading deficits. Above each bar is number of patients with each anomaly/total number of patients sampled. ${ }^{*} p<0.001$, ${ }^{\dagger} p=0.003$. PTSD $=$ posttraumatic stress disorder.

without were taking at least one medication with known visual side effects, and the difference was significant: Fisher exact test, $p=0.02$. Thirty-three of the $59(56 \%)$ patients without PTSD had other psychological diagnoses including depression, mood disorder, anxiety, and agitation. Of these 33 patients, 28 were taking at least one of the medications listed in Table 3. Trazodone has been reported to cause visual side effects in up to 14 percent of outpatients [32] and was the most common medication with visual side effects used by the patients in this study. More patients with PTSD than patients without PTSD were on Trazodone ( $46 \%$ vs $36 \%$ ), but this difference was not significant, $\chi^{2}(1)=0.76, p=0.38$.

PTSD was significantly associated with mTBI in these patients. As with medication usage, TBI severity (mTBI vs moderate/severe TBI) has the potential to confound the association of PTSD with the vision results observed. To investigate the influence of these and other factors, logistic regression was conducted on the factors found significant in the univariate analyses (light sensitivity and reading symptoms) using PTSD presence $( \pm)$, age, medication use $( \pm$ ), TBI severity (mTBI or moderate/severe TBI), and injury mechanism (NBR or BR) as predictor variables. Controlling for these variables confirmed the univariate PTSD/vision findings (Table 4). Patients with PTSD were more likely to report light sensitivity and reading symptoms. No significant associa- tions of light sensitivity or reading symptoms with the other predictor variables were found.

\section{DISCUSSION}

Our retrospective review of 100 medical records revealed high rates of oculomotor/BV deficits in these veterans, all of whom had a history of TBI. In fact, one or more deficits were measured in 88 percent of the patients. However, there were no significant differences in oculomotor/BV deficits in patients with PTSD compared with those without. This suggests that vision dysfunction may be associated more with TBI than with PTSD in these patients, with the caveat that the high rates of oculomotor/BV deficits in these patients with TBI could be masking PTSD-related problems. In our patient population, the oculomotor/BV deficits may point more to internal, organic damage as seen in TBI. If confirmed by future studies, oculomotor function measurements may prove helpful in establishing a history of TBI in some patients [33]. This is important because treatment methods vary between TBI, an organic injury, and PTSD, a psychiatric disorder [34]. As in our patient population, however, TBI and PTSD are often comorbid and have overlapping signs and symptoms [35].

We examined four self-reported visual symptoms in this study-general visual symptoms, light sensitivity, diplopia, and reading symptoms. For each symptom, patients with PTSD reported problems more frequently than did patients without PTSD. For light sensitivity and reading symptoms, the complaint rate was significantly higher in the patients with PTSD compared with those without. These findings, combined with the BV/oculomotor function results shown previously, allow us to hypothesize that the reporting of visual symptoms in the absence of measurable vision function deficits might also aid in the differentiation of postconcussive symptoms from PTSD symptoms. The increased rates of visual symptoms in patients with PTSD could be related to other issues known to occur in patients with PTSD. PTSD-associated hypersensitivity and hyperarousal [36] may cause an increased awareness and reporting of visual problems in some patients. Sleeping difficulties and concentration problems in patients with PTSD [3] may also contribute to vision problems.

Literature documenting the effects of PTSD on vision function is sparse. A recent study by Pogoda et al. 
JRRD, Volume 51, Number 4, 2014

Table 3.

Medications with visual side effects taken by patients.

\begin{tabular}{|c|c|c|c|}
\hline Medication & Primary Uses & Visual Side Effects & No. \\
\hline Trazodone & Depression, insomnia & Blurred vision & 41 \\
\hline Oxycodone & Pain & Pupil size changes, vision changes & 19 \\
\hline Quetiapine & Schizophrenia, depression & Vision changes & 19 \\
\hline Sertraline & Depression & Blurred vision & 9 \\
\hline Amitriptyline & Depression & Blurred vision & 8 \\
\hline Venlafaxine & Depression & Vision changes & 4 \\
\hline Clonazepam & Seizures & Blurred vision & 3 \\
\hline Phenytoin & Seizures & Uncontrollable eye movements & 3 \\
\hline Gabapentin & Seizures & Double or blurred vision & 3 \\
\hline Levetiracetam & Seizures & Double vision & 3 \\
\hline Amantadine & Parkinson-like disorders & Blurred vision & 2 \\
\hline Modafinil & Excessive sleepiness & Difficulty seeing & 2 \\
\hline Gabapentin & Seizures & Double or blurred vision & 2 \\
\hline Dexamethasone & Inflammation & Vision problems & 1 \\
\hline Diazepam & Anxiety, muscle spasms & Blurred vision & 1 \\
\hline Lorazepam & Anxiety & Blurred vision & 1 \\
\hline Pregabalin & Neuropathic pain & Double or blurred vision & 1 \\
\hline Metoclopramide & Heartburn, ulcer & Vision problems & 1 \\
\hline Olanzapine & Schizophrenia & Vision changes & 1 \\
\hline Ondansetron & Nausea & Blurred vision, vision loss & 1 \\
\hline Risperidone & Schizophrenia & Vision problems & 1 \\
\hline
\end{tabular}

found that a PTSD diagnosis in OIF/OEF veterans increased the odds of reporting multisensory symptoms [24]. The definition of multisensory impairment included a triad of visual, hearing, and vestibular symptoms. Visual symptoms were reported by over 40 percent of the veterans, but no analysis specifically examining the relationship between PTSD and vision was made. A 2010 article addressing numerous aspects of PTSD refers to many vision deficits and symptoms that may be present in PTSD, including decreased visual acuity, stereovision, accommodation, $\mathrm{BV}$, and increased sensitivity to glare [37]. Unfortunately, no references directly linking any of these visual conditions to PTSD were given. Similarly, a 2012 report of neurotransmitter function in the oculomotor nucleus in rats states that PTSD in humans may be associated with symptoms of extraocular oblique muscle disorders, inward or vertical eye movement disorders, and ptosis [38]. Again, no references associating these vision disorders to PTSD were documented. The lack of studies addressing vision changes in PTSD means that clinicians must rely on experience and anecdotal reports when addressing vision issues in these patients.

Our findings of TBI-associated visual dysfunction are supported by others who have also documented visual disturbances and abnormal oculomotor and binocular system measurements after TBI [22,39-40]. Research has shown that BV problems are associated with a number of symptoms that can affect daily functioning including headaches, eye fatigue, asthenopia (eye strain), and reading problems [41-42]. Difficulties with reading can have negative effects on educational and vocational achievement, goals of many veterans returning from deployment. Therefore, all patients with a history of TBI 
Table 4.

Multivariate analyses of associations between predictors and two outcome variables, light sensitivity and reading symptoms.

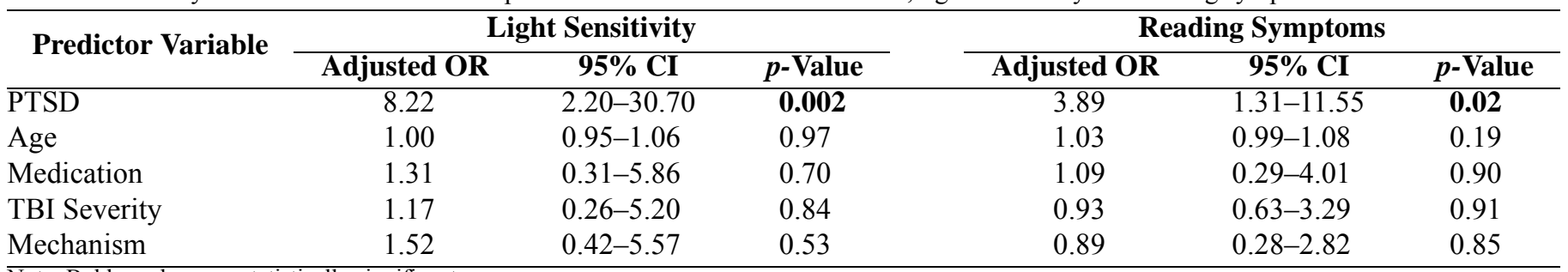

Note: Bold numbers are statistically significant.

$\mathrm{CI}=$ confidence interval, $\mathrm{OR}=$ odds ratio, $\mathrm{PTSD}=$ posttraumatic stress disorder.

merit a complete eye examination with a provider who is experienced and knowledgeable in the examination and treatment of patients with TBI.

The current study found higher rates of visual symptom reporting and of use of medication with visual side effects in patients with PTSD than in those without. The visual side effects of the medications prescribed to our subject population include blurred vision and altered pupil function, as well as vague effects referred to as "vision changes" or "vision problems" [31]. Multivariate analyses showed that medication use did not contribute to the higher frequency of patients with PTSD reporting visual symptoms. This finding is consistent with an article by Han et al. in a study of medication effects on selfreported visual symptoms or diagnosis in 220 patients with either TBI or cerebrovascular accident [43]. They concluded that the TBI or cerebrovascular accident diagnoses, but not medication intake, affected symptoms and diagnoses.

A PTSD diagnosis was significantly associated with mTBI in this study. This finding is in agreement with others who have found that a history of mTBI increases the chances of developing PTSD compared with patients with no TBI or with other injuries [20]. Conversely, some research has found that PTSD development is less likely after moderate/severe TBI, attributable to the increased length and severity of LOC and PTA that occur after injury [44]. It is important to recognize that PTSD can occur after TBI, regardless of the cause of or severity of the injury.

Increased age was also significantly associated with a diagnosis of PTSD in the current study. This finding runs counter to some studies that have found younger age to be a risk factor for developing PTSD [45-46]. However, in a study of $201 \mathrm{OIF} / \mathrm{OEF}$ veterans, Gellis et al. found no association of age with a PTSD diagnosis [47]. The reason for our finding is unclear. The two oldest patients in our sample were 62 and $63 \mathrm{yr}$ of age and each had diagnoses of PTSD and a history of NBR-TBI. However, age remained significantly greater in patients with PTSD even after these two patients were removed from the analysis.

Finally, more research is needed concerning PTSD, medication side effects, vision, and their interrelationships. While the current study examines these issues, it is limited by the lack of a PTSD- and TBI-free control group, the varying intervals between injury and examination, and its retrospective design. Future prospective studies, with controls, will further scientific understanding of these complex conditions and help ensure optimal diagnosis and treatment for patients with TBI, PTSD, or comorbidity.

\section{CONCLUSIONS}

Both physical and psychological traumas are unfortunate consequences of war. TBI and PTSD often occur in veterans of the Iraq and Afghanistan wars and other wounded warriors and are frequently comorbid. However, both conditions can happen to anyone at any time, including civilians. Both TBI and PTSD are associated with numerous adverse signs and symptoms, many of which overlap [35]. Thus, determining if a problem is secondary to TBI, PTSD, or both becomes difficult. TBIrelated changes in vision function are being increasingly documented [21-22,39], but information on how PTSD affects vision is not as well studied.

Vision testing results from the 100 patients, all with TBI, revealed high frequencies of visual symptoms and of vision function deficits. In terms of objective deficits, no differences in oculomotor/BV deficits were found in the 41 percent of patients with PTSD compared with those without. However, the presence of (subjective) 
visual symptoms was reported at higher rates in patients with PTSD than in patients without PTSD, implying that the PTSD condition enhanced the patient's sensitivity or emotional response to the underlying deficits when present. Thus, the organic neurotrauma from TBI may be a factor in the oculomotor deficits that were found [21], while PTSD-associated hypersensitivity [36] may have caused an increase in reported visual symptoms in these patients. Determining to what extent reported symptoms are attributable to TBI, PTSD, or both are directions for future research.

\section{ACKNOWLEDGMENTS}

\section{Author Contributions:}

Study concept and design: G. L. Goodrich, G. L. Martinsen.

Acquisition of data: H. M. Flyg, J. Kirby, G. L. Martinsen.

Analysis and interpretation of data: G. L. Martinsen, D. W. Garvert,

G. L. Goodrich.

Drafting of manuscript: G. L. Martinsen, G. L. Goodrich, C. W. Tyler. Critical revision of manuscript for important intellectual content:

G. L. Goodrich, G. L. Martinsen, C. W. Tyler.

Statistical analysis: D. W. Garvert, G. L. Martinsen, G. L. Goodrich.

Obtained funding: C. W. Tyler.

Administrative, technical, or material support: G. L. Goodrich, G. L. Martinsen, H. M. Flyg, J. Kirby, D. W. Garvert, C. W. Tyler. Study supervision: G. L. Goodrich.

Financial Disclosures: The authors have declared that no competing interests exist.

Funding/Support: This material was based on work supported in part by the Department of Veterans Affairs Quality Enhancement Research Initiative (grant RRP 11-008) and by a subcontract to Dr. Goodrich of Department of Defense grant W81XWH-11-2-0066 to Dr. Tyler.

Institutional Review: Approval was obtained from the Institutional Review Board and the Department of Veterans Affairs Palo Alto Health Care System Research and Development Committee prior to initiation of this research.

\section{REFERENCES}

1. Bentley S. A short history of PTSD: From Thermopylae to Hue soldiers have always had a disturbing reaction to war [Internet]. Silver Spring (MD): The VVA Veteran; 2005 [cited 2012 Sept 5]; Available from: http://www.vva.org/ archive/TheVeteran/2005 03/feature HistoryPTSD.htm

2. Gersons BP, Carlier IV. Post-traumatic stress disorder: The history of a recent concept. Br J Psychiatry. 1992;161:742-48. [PMID:1483159] http://dx.doi.org/10.1192/bjp.161.6.742

3. O'Donnell ML, Creamer M, Bryant RA, Schnyder U, Shalev A. Posttraumatic disorders following injury: An empiri- cal and methodological review. Clin Psychol Rev. 2003; 23(4):587-603. [PMID:12788111] http://dx.doi.org/10.1016/S0272-7358(03)00036-9

4. Litz BT, Schlenger WE. PTSD in service members and new veterans of the Iraq and Afghanistan Wars: A bibliography and critique. PTSD Res Quarter. 2009;20(1):1-3.

5. Bryant RA. Posttraumatic stress disorder and traumatic brain injury: Can they co-exist? Clin Psychol Rev. 2001; 21(6):931-48. [PMID:11497213] http://dx.doi.org/10.1016/S0272-7358(00)00074-X

6. DSM criteria for PTSD. Washington (DC): Department of Veterans Affairs [cited 2012 Sept 12; updated 2014 Jan 3]; Available from: http://www.ptsd.va.gov/professional/ PTSD-overview/dsm5 criteria ptsd.asp

7. Tanielian T, Jaycox LH. Invisible wounds of war: Summary and recommendations for addressing psychological and cognitive injuries. Santa Monica (CA): RAND; 2008.

8. Jaffee MS, Meyer KS. A brief overview of traumatic brain injury (TBI) and post-traumatic stress disorder (PTSD) within the Department of Defense. Clin Neuropsychol. 2009;23(8):1291-98. [PMID:19882472] http://dx.doi.org/10.1080/13854040903307250

9. Sayer NA, Chiros CE, Sigford B, Scott S, Clothier B, Pickett T, Lew HL. Characteristics and rehabilitation outcomes among patients with blast and other injuries sustained during the Global War on Terror. Arch Phys Med Rehabil. 2008;89(1):163-70. [PMID:18164349] http://dx.doi.org/10.1016/j.apmr.2007.05.025

10. Owens BD, Kragh JF Jr, Wenke JC, Macaitis J, Wade CE, Holcomb JB. Combat wounds in operation Iraqi Freedom and operation Enduring Freedom. J Trauma. 2008;64(2): 295-99. [PMID:18301189] http://dx.doi.org/10.1097/TA.0b013e318163b875

11. Ling GS, Ecklund JM. Traumatic brain injury in modern war. Curr Opin Anaesthesiol. 2011;24(2):124-30. [PMID:21301332] http://dx.doi.org/10.1097/ACO.0b013e32834458da

12. Weichel ED, Colyer MH, Ludlow SE, Bower KS, Eiseman AS. Combat ocular trauma visual outcomes during operations iraqi and enduring freedom. Ophthalmology. 2008; 115(12):2235-45. [PMID:19041478] http://dx.doi.org/10.1016/j.ophtha.2008.08.033

13. Management of Concussion/mTBI Working Group. VA/ DoD Clinical Practice Guideline for Management of Concussion/Mild Traumatic Brain Injury. J Rehabil Res Dev. 2009;46(6):CP1-68. [PMID:20108447]

14. Powell JM, Ferraro JV, Dikmen SS, Temkin NR, Bell KR. Accuracy of mild traumatic brain injury diagnosis. Arch Phys Med Rehabil. 2008;89(8):1550-55. [PMID:18597735] http://dx.doi.org/10.1016/j.apmr.2007.12.035 
15. Summerall EL. Traumatic brain injury and PTSD. [cited 2012 Sept 13]; Available from: http://www.ptsd.va.gov/ professional/co-occurring/traumatic-brain-injury-ptsd.asp

16. TBI community [Internet]. Houston (TX): TIRR Memorial Hermann; 2009 [cited 2012 May 8]; Available from: http:// www.tbicommunity.org/resources/index.htm

17. Hoge CW, McGurk D, Thomas JL, Cox AL, Engel CC, Castro CA. Mild traumatic brain injury in U.S. Soldiers returning from Iraq. N Engl J Med. 2008;358(5):453-63. [PMID:18234750] http://dx.doi.org/10.1056/NEJMoa072972

18. Vasterling JJ, Verfaellie M, Sullivan KD. Mild traumatic brain injury and posttraumatic stress disorder in returning veterans: Perspectives from cognitive neuroscience. Clin Psychol Rev. 2009;29(8):674-84. [PMID:19744760] http://dx.doi.org/10.1016/j.cpr.2009.08.004

19. King NS. PTSD and traumatic brain injury: Folklore and fact? Brain Inj. 2008;22(1):1-5. [PMID:18183503] http://dx.doi.org/10.1080/02699050701829696

20. Bryant R. Post-traumatic stress disorder vs traumatic brain injury. Dialogues Clin Neurosci. 2011;13(3):251-62. [PMID:22034252]

21. Ciuffreda KJ, Kapoor N, Rutner D, Suchoff IB, Han ME, Craig S. Occurrence of oculomotor dysfunctions in acquired brain injury: A retrospective analysis. Optometry. 2007;78(4):155-61. [PMID:17400136] http://dx.doi.org/10.1016/j.optm.2006.11.011

22. Brahm KD, Wilgenburg HM, Kirby J, Ingalla S, Chang CY, Goodrich GL. Visual impairment and dysfunction in combat-injured servicemembers with traumatic brain injury. Optom Vis Sci. 2009;86(7):817-25.

[PMID:19521270] http://dx.doi.org/10.1097/OPX.0b013e3181adff2d

23. Goodrich GL, Flyg HM, Kirby JE, Chang CY, Martinsen GL. Mechanisms of TBI and visual consequences in military and veteran populations. Optom Vis Sci. 2013;90(2): 105-12. [PMID:23314131] http://dx.doi.org/10.1097/OPX.0b013e31827f15a1

24. Pogoda TK, Hendricks AM, Iverson KM, Stolzmann KL, Krengel MH, Baker E, Meterko M, Lew HL. Multisensory impairment reported by veterans with and without mild traumatic brain injury history. J Rehabil Res Dev. 2012; 49(7):971-84. [PMID:23341273]

http://dx.doi.org/10.1682/JRRD.2011.06.0099

25. Burgess P, E Sullivent E, M Sasser S, M Wald M, Ossmann E, Kapil V. Managing traumatic brain injury secondary to explosions. J Emerg Trauma Shock. 2010;3(2):164-72. [PMID:20606794] http://dx.doi.org/10.4103/0974-2700.62120

26. Mac Donald CL, Johnson AM, Cooper D, Nelson EC, Werner NJ, Shimony JS, Snyder AZ, Raichle ME, Witherow JR, Fang R, Flaherty SF, Brody DL. Detection of blast- related traumatic brain injury in U.S. military personnel. N Engl J Med. 2011;364(22):2091-2100.

[PMID:21631321]

http://dx.doi.org/10.1056/NEJMoa1008069

27. Warden D. Military TBI during the Iraq and Afghanistan wars. J Head Trauma Rehabil. 2006;21(5):398-402.

[PMID:16983225]

http://dx.doi.org/10.1097/00001199-200609000-00004

28. Maples WC, Atchley J, Ficklin T. Northeastern State University College of Optometry's oculomotor norms. J Behav Optom. 1992;3(6):143-50.

29. Hofstetter HW. A comparison of Duane's and Donder's tables of the amplitude of accommodation. Am J Optom Arch Am Acad Optom. 1944;21:345-63. http://dx.doi.org/10.1097/00006324-194409000-00001

30. Bower KM. When to Use Fisher's Exact Test, American Society for Quality. Six Sigma Forum Magazine. 2003; 2(4):35-37.

31. PubMed Health. Drugs A-Z [Internet]. Bethesda (MD): National Center for Biotechno.logy Information; [cited 2012 Oct 30]; Available from: http://www.ncbi.nlm.nih.gov/ pubmedhealth/s/drugs and supplements/a/

32. Drugs.com. Trazodone [Internet]. Auckland (New Zealand): Drugsite Trust; 2014 [cited 201220 Nov]; Available from: http://www.drugs.com/pro/trazodone.html

33. Bass CR, Panzer MB, Rafaels KA, Wood G, Shridharani J, Capehart B. Brain injuries from blast. Ann Biomed Eng. 2012;40(1):185-202. [PMID:22012085]

http://dx.doi.org/10.1007/s10439-011-0424-0

34. Brenner LA, Bahraini N, Hernández TD. Perspectives on creating clinically relevant blast models for mild traumatic brain injury and post traumatic stress disorder symptoms. Front Neurol. 2012;3(31). [PMID:22408635]

35. Stein MB, McAllister TW. Exploring the convergence of posttraumatic stress disorder and mild traumatic brain injury. Am J Psychiatry. 2009;166(7):768-76.

[PMID:19448186]

http://dx.doi.org/10.1176/appi.ajp.2009.08101604

36. Kendall-Tackett KA. Physiological correlates of childhood abuse: Chronic hyperarousal in PTSD, depression, and irritable bowel syndrome. Child Abuse Negl. 2000;24(6):799-810. [PMID:10888019] http://dx.doi.org/10.1016/S0145-2134(00)00136-8

37. Trachtman JN. Post-traumatic stress disorder and vision. Optometry. 2010;81(5):240-52. [PMID:20435270] http://dx.doi.org/10.1016/j.optm.2009.07.017

38. Liu D, Xiao B, Han F, Luo F, Wang E, Shi Y. Changes in 5HT1A receptor expression in the oculomotor nucleus in a rat model of post-traumatic stress disorder. J Mol Neurosci. 2012;49(2):360-8. [PMID:22930314] http://dx.doi.org/10.1007/s12031-012-9874-6 
39. Stelmack JA, Frith T, Van Koevering D, Rinne S, Stelmack TR. Visual function in patients followed at a Veterans Affairs polytrauma network site: An electronic medical record review. Optometry. 2009;80(8):419-24. [PMID:19635432] http://dx.doi.org/10.1016/j.optm.2009.02.011

40. Dougherty AL, MacGregor AJ, Han PP, Heltemes KJ, Galarneau MR. Visual dysfunction following blast-related traumatic brain injury from the battlefield. Brain Inj. 2011; 25(1):8-13. [PMID:21117919] http://dx.doi.org/10.3109/02699052.2010.536195

41. Borsting E, Rouse MW, De Land PN. Prospective comparison of convergence insufficiency and normal binocular children on CIRS symptom surveys. Convergence Insufficiency and Reading Study (CIRS) group. Optom Vis Sci. 1999;76(4):221-28. [PMID:10333184] http://dx.doi.org/10.1097/00006324-199904000-00025

42. Scheiman M, Mitchell GL, Cotter S, Cooper J, Kulp M, Rouse M, Borsting E, London R, Wensveen J; Convergence Insufficiency Treatment Trial Study Group. A randomized clinical trial of treatments for convergence insufficiency in children. Arch Ophthalmol. 2005;123(1): 14-24. [PMID:15642806] http://dx.doi.org/10.1001/archopht.123.1.14

43. Han MH, Craig SB, Rutner D, Kapoor N, Ciuffreda KJ, Suchoff IB. Medications prescribed to brain injury patients: A retrospective analysis. Optometry. 2008;79(5):252-58. [PMID:18436165] http://dx.doi.org/10.1016/j.optm.2008.01.001

44. Warden DL, Labbate LA, Salazar AM, Nelson R, Sheley E, Staudenmeier J, Martin E. Posttraumatic stress disorder in patients with traumatic brain injury and amnesia for the event? J Neuropsychiatry Clin Neurosci. 1997;9(1):18-22. [PMID:9017524]

45. Seal KH, Bertenthal D, Miner CR, Sen S, Marmar C. Bringing the war back home: Mental health disorders among 103,788 US veterans returning from Iraq and Afghanistan seen at Department of Veterans Affairs facilities. Arch Intern Med. 2007;167(5):476-82.

[PMID:17353495]

http://dx.doi.org/10.1001/archinte.167.5.476

46. Grieger TA, Cozza SJ, Ursano RJ, Hoge C, Martinez PE, Engel CC, Wain HJ. Posttraumatic stress disorder and depression in battle-injured soldiers. Am J Psychiatry. 2006;163(10):1777-83, quiz 1860. [PMID:17012689] http://dx.doi.org/10.1176/appi.ajp.163.10.1777

47. Gellis LA, Mavandadi S, Oslin DW. Functional quality of life in full versus partial posttraumatic stress disorder among veterans returning from Iraq and Afghanistan. Prim Care Companion J Clin Psychiatry. 2010;12(3). [PMID:20944775]

Submitted for publication February 25, 2013. Accepted in revised form December 16, 2013.

This article and any supplementary material should be cited as follows:

Goodrich GL, Martinsen GL, Flyg HM, Kirby J, Garvert DW, Tyler CW. Visual function, traumatic brain injury, and posttraumatic stress disorder. J Rehabil Res Dev. 2014;51(4):547-58.

http://dx.doi.org/10.1682/JRRD.2013.02.0049

ResearcherID/ORCID: Gary L. Martinsen, OD, PhD: F4838-2014; Donn W. Garvert, MS: F-4724-2014; Gregory L. Goodrich, PhD: F-8388-2014

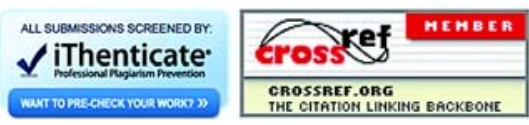

